\title{
Said Nursî’de Ölüm Sonrası Yeniden Diriliş
}

Nezip KISTIR 


\title{
(C) Copyright 2020
}

Bu kitabın, basım, yayın ve satış hakları Akademisyen Kitabevi A.Ş.'ne aittir. Anılan kuruluşun izni alınmadan kitabın tümü ya da bölümleri mekanik, elektronik, fotokopi, manyetik kağıt ve/veya başka yöntemlerle çoğaltılamaz, basılamaz, dağıtılamaz. Tablo, şekil ve grafikler izin alınmadan, ticari amaçh kullanılamaz. Bu kitap T.C. Kültür Bakanlı̆̆ bandrolü ile satılmaktadır.

\section{ISBN}

978-605-258-992-2

\section{Kitap Adı}

Said Nursî̉e Ölüm Sonrası Yeniden Diriliş

\author{
Yazar \\ Nezip KISTIR \\ Yayın Koordinatörü \\ Yasin Dilmen \\ Sayfa ve Kapak Tasarımı \\ Akademisyen Dizgi Ünitesi \\ Yayıncı Sertifika No \\ 47518 \\ Baskı ve Cilt \\ Sonçağ Matbaacılık \\ Bisac Code \\ REL037060
}

\section{GENEL DAĞITIM}

\section{Akademisyen Kitabevi A.Ş.}

Halk Sokak 5 / A

Yenişehir / Ankara

Tel: o312 4311633

siparis@akademisyen.com

\section{www . a kademisyen . com}




\section{ÖNSÖZ}

Kelâm ilmi genelde İslâm’n özelde inanç esaslarının tespit, temellendirme ve savunuculuğunu üstlenmiştir. Kelâm ilmi geliştirmiş olduğu yöntemi, günün ihtiyaçlarına göre bir takım yenilikler ile birlikte günümüze kadar ulaştırmıştır.

İnceleme konusu yaptığımız Risâle-i Nur Külliyatı çağımıza yakın bir zamanda kaleme alınmış eserleri ihtiva etmektedir. Bu eserler birer kelâm eseri olmamakla beraber inanç esasları yoğun olarak ele alınan risâlelerdir. Böylelikle kelâmî yönü ağır basan eserler olarak değerlendirilebilir.

Said Nursî, hayatın tamamını kapsayan bir batılılaşmaya karşı çıkmış ve çözümün sadece İslâm’a sımsıkı tutunmak sûretiyle gerçekleşebileceğini beyan etmiştir. Yaşadığı dönemde ortaya çıkan İslâm karşıtı akımlara karşı İslâm’ın temel prensiplerini savunup onların iddialarının tutarsızlıklarını ortaya koymaya çalışmıştır. Böylece İslâm’n temel prensiplerinden ödün vermeyen bir toplum oluşmasını temenni etmiştir.

Eserlerinde ağır ve ağdalı bir dil kullanan Said Nursî ilerleyen dönemlerinde bu dilini biraz olsun sadeleştirmiştir. Lakin ağır ve uzun cümlelerden oluşan kendine has mana ve cümle düzenlerini hep korumuştur. Ayrıca eserlerinde kendisini genellikle "Eski Said" ve "Yeni Said" olarak tanımlayarak bazı görüşlerinin eskisi gibi olmadığını okuyucularına beyan etmiştir.

Bizim inceleme alanımız olan haşir (tekrar diriltilme) "Sözler” kitabında ayrıntılı bir şekilde ve toplu olarak incelenmiştir. Şualar, Lemalar, İşârâtü'l-i’câz, Asây-1 Musa, Mesnevî-i Nuriye, Mektubat ve diğer kitaplarında da haşre değinmiş lakin bir kısmında tekrar ederek bir kısmında da tekrarı genişleterek Onuncu 
Söz olan haşir bahsine destek vermiştir. Haşri ispat ederken gerek aklî gerek naklî delilleri sıklıkla kullanarak muhataplarının akıllarına hitap etmeyi ve de iman edenlerin kalplerini mutmain etmeyi hedeflemiştir. Aynı zamanda anlaşılmasını kolaylaştırmak için temsillere sıklıkla yer vermiştir.

Said Nursî ve yazmış olduğu eserler hakkında bazı akademik çalışmaların olduğunu biliyoruz. Fakat onun "haşir" konusunda yani ölüm sonrası, âhiret hayatı için tekrar dirilmenin neliği konusunda müstakil bir çalışmanın olmaması bizi böyle bir çalışmaya sevk etti. Bu çalışmayı yaparken onun ele aldığı meseleleri eleştiri ve değerlendirme süzgecinden geçirerek ortaya koymaya çalıştık.

$\mathrm{Bu}$ tezi hazırlarken Said Nursînin kendi eserlerini temel aldık, zaman zaman da ilgili olan diğer kaynaklara müracaat ettik. Mümkün olduğu kadar objektiflik prensibine bağlı kalmaya çalıştık, yerinde eleştiri ve değerlendirmelerle incelememizi tamamladik.

Araştırma konusu olarak "Said Nursîde Ölüm Sonrası Yeniden Diriliş" adlı konuyu seçmemizin temel amacı, ilâhî dinlere ve bu dinlerin inanç esaslarına karşı son dönemlerde artan inkârcı tutumlardır. Özellikle Ateizm ve Deizm'in söylemlerinin yüksek sesle dillendirildiği son dönemlerde bu tür aklî ve naklî delillerle inanç esaslarının yeniden gündeme getirilmesi bir ihtiyaç olmuştur. Said Nursînin risâleler vasitasıyla insanlara asıl vermek istediği Allah’n (celle celaluhu) varlığı ve âhiretin varlığının ispatıdır. Haşir konusu da genelde bu bağlamda değinilen bir konudur. Bu nedenle haşir ile ilgili görüşler çok dağınık bir haldedir. Sürekli âhiretin varlığı ve Allah’’n (celle celaluhu) varlığı ile ilişkilendirilmektedir. Bizde çalışmamızda yer yer bu bağlamda konuyu işlemeye çalıştık. 
Giriş ve iki bölüm olarak üç kısımdan oluşan bu çalışmamızın, giriş bölümünde haşir, neşir, mahşer, ba’s ve acbü-'z-zeneb kavramları ile beraber Risâle-i Nur'daki üslûp hakkında bilgi verilmiştir. Birinci bölümde Risâle-i Nur'u inceledikten sonra Said Nursînin ispatları kısımlara bölünmüş ve haşrin imkânı başlıklar halinde incelenmiştir. Bu bölümde haşrin aklî ve naklî delillerine yer verilmiştir. İkinci bölümde ise haşrin mahiyeti hakkında bilgi verilmiştir.

$\mathrm{Bu}$ çalışmada izlediğimiz yol ise şöyledir: Said Nursî, eserlerinde incelediği konuları sistematik olarak incelememiştir. İncelediği konuları, anlatımını yaptığı bahislerin içerisine serpiştirmiştir. İşlediği konular tekrar ediyor gibi gözükse de farklı deliller için yeniden ele aldığından tekrar etmiştir. Biz de bu tekrarları ilgili başlıklar altında inceledik ve sistematik olmayan delilleri ayrı başlıklar halinde toplayıp belli bir sistematik düzen içerisinde incelemeye çalıştık. Bahsetmiş olduğu delilleri eleştirel bir süzgeçten geçirmek sûretiyle inceleyip anlaşılmasını sağlamaya çalıştık.

Bir yüksek lisans tezi olarak hazırladığımız bu çalışmada danışmanlığımı yürüten ve her türlü fikir ve düşüncesini benimle paylaşan danışman hocam, Doç. Dr. Mustafa BOZKURT ve yine düşüncelerinden istifade ettiğim Prof. Dr. Hulûsi ARSLAN hocalarıma teşekkür ederim. Ek olarak her yardım talebinde bulunduğumda yardımlarını esirgemeyen Doç. Dr. Hüseyin Hüsnü KOYUNOĞLU hocam ile tezin yazım ve imla kurallarının incelenmesi konusunda yoğun çaba sarf eden Muhammed Önal YAĞIR’a teşekkür ederim.

Başarıya ulaşmak ancak Allah’nn (celle celaluhu) yardımıyla mümkündür.

Nezip KISTIR 


\section{İÇINDEKILER}

\section{GİRIŞ}

1. Araştırmanın Temel Kavramları .................................................... 1

1.1. Haşir ...................................................................................... 1

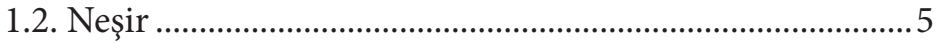

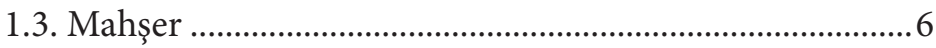

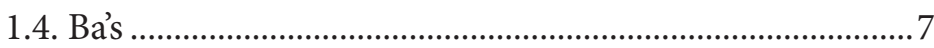

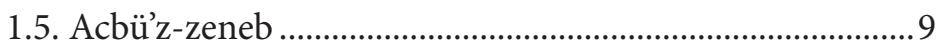

2. Risâle-i Nur'daki Üslûp ...........................................................10

2.1. Dil açısından ........................................................................... 10

2.2. Yöntem Açısından .................................................................11

\section{BİRİNCİ BÖLÜM}

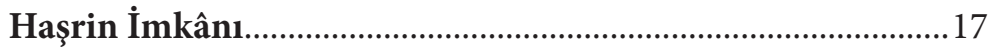

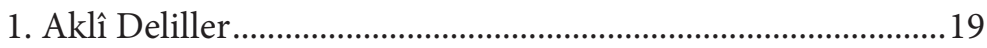

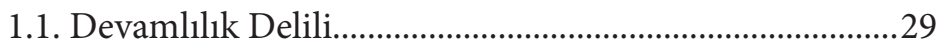

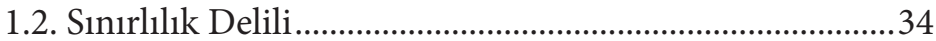

1.3. Allah'in (celle celaluhu) İsimleri ve Sifatları Üzerinden Getirilen Deliller ........................................................................... 41

1.3.1. Rubûbiyet ve Merhamet...............................................43

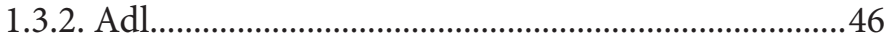

1.3.3. Cevâd ve Cemîl .............................................................51

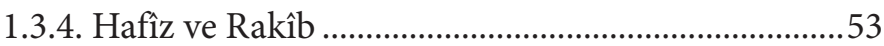

1.3.5. Vahdâniyet ve Kudret .................................................55

1.3.6. Cemîl, Celîl ve Bâkî̀......................................................61

1.3.7. Hay, Kayyûm, Muhyî ve Mümît...................................63

1.3.8. Rahmân ve Rahîm ........................................................65

1.4. Gaye ve Nizam Delili............................................................67 
viii

1.4.1. Bahar Üzerinden ............................................................68

1.4.2. Düzen Üzerinden .......................................................... 70

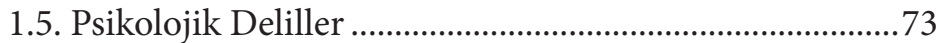

1.5.1. Ölüm Üzerinden ...........................................................74

1.5.2. Sonsuzluk Üzerinden ................................................77

1.5.3. Sevgi Üzerinden ............................................................79

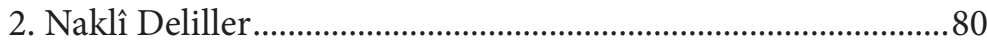

2.1. İlk Yaratılışın Dirilişe Delil Oluşu ......................................84

2.2. Tabiatın Canlanmasının Dirilişe Delil Oluşu ...................87

2.3. Değişimin ve Kıyâmetin Dirilişe Delil Oluşu ...................91

\section{İKİNCİ BÖLÜM}

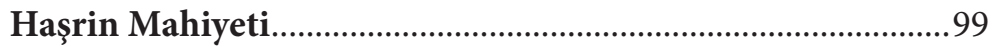

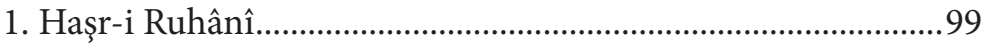

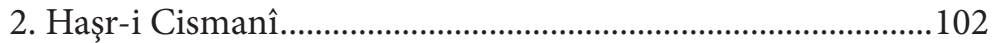

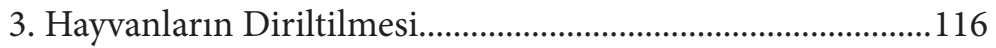

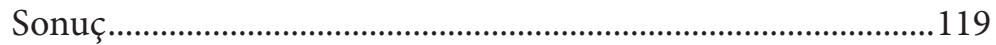

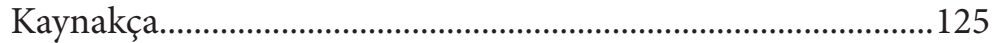

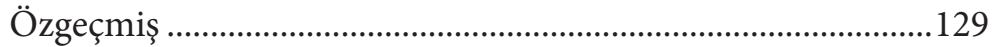


Insanlar uykudadır, ölünce uyanırlar.

Hz. Muhammed (s.a.v.) 


\section{KAYNAKÇA}

Abdurrahman b. Muhammed Ebû Zeyd Veliyyüddîn İbn Haldûn. $M u-$ kaddime. Ed. Süleyman Uludağ. 2 Cilt. İstanbul: Dergah Yayınları, 1983.

Aktaş, Mehmet. Kemalpaşazâde’nin Zihnî Varlık Risalesi: Tahkîk ve Değerlendirme. Yüksek Lisans Tezi, Marmara Üniversitesi, 2014.

Alper, Ömer Mahir. “İbn Sînâ ve İbn Sînâ Okulu”. İslâm Felsefesi Tarih ve Problemler. Ed. M. Cüneyt Kara. 251-283. Ankara: İsam Yayınları, 2016.

Aslan, Harun. Fahreddin Râzî̀de Diriliş ve Haşr. Yüksek Lisans Tezi, Necmettin Erbakan Üniversitesi, 2017.

Aslan, Hulusi - Bozkurt, Mustafa. Sistematik Kelam. Malatya: TDV Yayinları, 2018.

Avcı, Casim. "İslâm Öncesi Arabistan ve Araplarda Dinî, Sosyo-Kültürel Hayat". İlk Dönem İslâm Tarihi. Eskişehir: Anadolu Üniversitesi Yayınları, 2015.

Bakkal, Ali. "Bediüzzaman Said Nursînin Hadisleri Yorumlama Metodu". Hadis Özel Sayısı. 4 (2017).

Bilmen, Ömer Nasuhi. Büyük İslam İlmihali. İstanbul: Yasin Yayınevi, 2015.

Bulut, Halil İbrahim. İslam Mezhepleri Tarihi. Ankara: Diyanet İşleri Başkanlığı Yayınları, 2016.

Cemaluddîn Muhammed b. Mukrim İbn Manzûr. "be-a-se". Lisânu’l-Arab. Beyrut: Dâru Sâdir, 1990.

Cemaluddîn Muhammed b. Mukrim İbn Manzûr. "ha-şe-re". Lisânu'l-Arab. Beyrut: Dâru Sâdir, 1990.

Cemaluddîn Muhammed b. Mukrim İbn Manzûr. "ne-şe-re". Lisânu'l-Arab. Beyrut: Dâru Sâdir, 1990.

Dikmen, Mehmet. Esmaü’l Hüsnâ ve Hayatımıza Yansımaları. İstanbul: Cihan Yayınları, 2014.

Doğan, Muhammed. Yirmi Beşinci Mektub Yâsin Sûresinin Tefsiri. İstanbul: Semendel Yayınları, 2016.

Doğan, Muhammed Ali. Onuncu Söz Haşir Risalesi. İstanbul: Tahşiye Yayınları, 2011.

Ebû Mansûr el-Mâtürîdî. Te’vîlâtü’l Kur'ân Tercümesi. Ed. Yusuf Şevki Yavuz. Trc. Bekir Topaloğlu. İstanbul: Ensar Neşriyat, 2015.

Ebû Mansûr el-Mâtürîdî. Te’vîlâtü’l Kur'ân Tercümesi. Ed. Yusuf Şevki Yavuz. Trc. Kemal Sandıkçı. İstanbul: Ensar Neşriyat, 2016. 
Erdem, Hüsameddin. “Deizm”. Türkiye Diyanet Vakfı İslâm Ansiklopedisi. İstanbul: TDV Yayınları, 1994.

Erkol, Ahmet. "Seyfüddin Amidi’ye Göre Cismani Haşr”. İlahiyat Fakültesi Dergisi 2 (2000).

Fatiş, Emrullah. "Gazalî ve İbn Sinẩnın Cismani Haşre Yaklaşımı”. Kelam Araştırmaları 12/2 (2014): 147-170.

Fazlur Rahman. Ana Konularıyla Kur'an. Trc. Açıkgenç Alparslan. Ankara: Ankara Okulu Yayınları, 2016.

Gazzâlî. Tehâfütü'l-Felâsife. Trc. Bekir Sadak. İstanbul: Ahsen Yayınları, 2002.

Görgen, Salih. Muhammed Hamdi Yazır’a Göre Ölüm ve Ölüm Sonrası Varoluş. Yüksek Lisans Tezi, Erciyes Üniversitesi, 2010.

Hitchcock, Mark. "Hırıstiyanlıkta Ölümden Sonraki Hayat”. Trc. Süleyman Turan. 2005. 297-314.

Hücvirî. Hakikat Bilgisi Keşfu'l-Mahcûb. İstanbul: Dergâh Yayınları, 2010.

“İlk Kim Buldu”. İlk Kim Buldu. t.y. http://www.ilkkimbuldu.com/parmak-izini-kim-buldu/.

İmam-1 Azam Ebu Hanife. Fıkh-ı Ekber. Trc. Mustafa Kasadar. İstanbul: Ravza Yayınları, 2015.

Karaduman, Emrah. Kur'ân ve Sünnette Haşir ve Mahşer. Yüksek Lisans Tezi, Necmettin Erbakan Üniversitesi, 2013.

Kılavuz, A. Saim. Ana Hatlarıyla İslam Akaidi ve Kelamia Giriş. İstanbul: Ensar Yayınları, 2015.

Kistır, Nezip. Ahlak’ı İhyası. t.y.

Koçar, Musa. Eleştirel Açıdan Said Nursînnin Kelâmî Görüşleri. Doktora Tezi, Marmara Üniversitesi, 1999.

Koytak, Nazlı Sinem. 7-11 Yaş Grubundaki Çocuklarda Ölüm Kavramı Ve Ölüm Kaygısının Araştırılması. Yüksek Lisans Tezi, İstanbul Üniversitesi, 2008.

Köftegül, Özlem. Yetişkin Bireylerde Ölüm Kaygısı ve Dindarlık. Yüksek Lisans Tezi, Çanakkale Onsekiz Mart Üniversitesi, 2018.

Küçükceranlar, Ömer. Kur'an'a Göre İnkârcıların Haşir Sonrası İtiraf, Pişmanlık ve Yalvarış Dolu Hazin Tavırları. Yüksek Lisans Tezi, Ankara Üniversitesi, 2011.

Muhammed Gazâli. İhyâ-u Ulûmi'd-Dîn. Trc. Mehmet Müftüoğlu. 8 Cilt. İstanbul: Çelik Yayınevi, 2016.

Muhammed Gazâli. İhyâ-u Ulûmi'd-Dîn. Trc. Mehmet Müftüoğlu. 8 Cilt. İstanbul: Çelik Yayınevi, 2016.

Muhammed Gazâli. Kimyâ-yı Saadet. Trc. Ali Arslan. İstanbul: Merve Yayınları, 2014. 
Nûreddin es-Sâbûnî. Mâtürîdiyye Akaidi. Trc. Bekir Topaloğlu. İstanbul: Marmara Üniversitesi İlahiyat Fakültesi Vakfı Yayınları, 2017.

Özarslan, Selim. Günümüz Kelâm İnanç Problemleri. Ankara: Nobel Yayınları, 2016.

Öztoprak, Mustafa. "Said Nursînin Peygamber Anlayışı Üzerine Bazı Mülahazalar". Iğdır Üniversitesi, İlahiyat Fakültesi Dergisi. 8 Ekim (2016).

Sa'duddîn Taftâzânî,. Şerhu'l-Akâid. Trc. Süleyman Uludağ. İstanbul: Dergah Yayınları, 2010.

Said Nursî. Âsâr-ı Bedî̀yye. İstanbul: Envâr Neşriyat, 2017.

Said Nursî. Asâ-yı Musa. İstanbul: Yeni Asya Neşriyat, 2006.

Said Nursî. Barla Lâhikası. İstanbul: Yeni Asya Neşriyat, 2004.

Said Nursî. Emirdă̆ Lâhikası. İstanbul: Yeni Asya Neşriyat, 2004.

Said Nursî. İman ve Küfür Muvazeneleri. İstanbul: Zehra Yayıncllı, 2004.

Said Nursî. İ̧̧ârâtü'l İ'câz. İstanbul: Yeni Asya Neşriyat, 2004.

Said Nursî. Kastamonu Lâhikası. İstanbul: Yeni Asya Neşriyat, 2000.

Said Nursî. Lemaalar. İstanbul: Yeni Asya Neşriyat, 2002.

Said Nursî. Mektubat. İstanbul: Yeni Asya Neşriyat, 1999.

Said Nursî. Mesnevi-i Nuriye. Trc. Abdulmecid Nursî. İstanbul: rnk Neşriyat, 2015.

Said Nursî. Muhakemat. İstanbul: Zehra Yayıncilık, 2003.

Said Nursî. Nur’un İlk Kapısı. İstanbul: Envâr Neşriyat, 1991.

Said Nursî. Sikke-i Tasdîk-i Gaybî. İstanbul: Zehra Yayıncılık, 2002.

Said Nursî. Sözler. İstanbul: Yeni Asya Neşriyat, 2006.

Said Nursî. Şuâlar. İstanbul: Yeni Asya Neşriyat, 2004.

Said Nursî. Tarihçe-i Hayat. İstanbul: Sözler Yayınevi, 1996.

Sarıçam, İbrahim. "Hz. Peygamber Dönemi”. İslâm Tarihi. Ed. Eyüp Baş. Ankara: Grafiker Yayınları, 2013.

Sevimli, Cevat. Kurân'da Haşr Kavramı. Yüksek Lisans Tezi, Uludağ Üniversitesi, 2006.

Seyyid, Kutub. Fîzılâl-il Kuran. Trc. M. Emin Saraç - İ. Hakkı Şengüler - Bekir Karlığa. İstanbul: Hikmet Yayınları, 1986.

Sharivkhan, Galimbek. Kur'an'da Ölüm Sonrası ve Reeankarnasyon. Selçuk Üniversitesi, 2010.

"Sorularla Risale". Sorularla Risale. t.y. https://sorularlarisale.com/cehennemde-azap-ceken-bir-insana-yok-olmak-ister-misin-dense-kabul-etmeyecek-mi-ustadin-yokluk.

"Sorularla Said Nursi". Sorularla Said Nursi. Erișim: 26 Aralık 2018. www.sorularlasaidnursi.com/risale-inur-gozuyle-hasir/. 
Şahin, İskender. Kur'an-ı Kerimide Diriliş. Dokuz Eylül Üniversitesi, 2012.

Şentürk, Lütfi - Yazıc1, Seyfettin. Güncel Dinî Meseleler. Ankara: Türkiye Diyanet Vakfı Yayınları, 2013.

Topaloğlu, Aydın. "Materyalizm”. Türkiye Diyanet Vakfi İslâm Ansiklopedisi. Ankara: TDV Yayınları, 2003.

Topaloğlu, Bekir. "Hudûs". Türkiye Diyanet Vakfı İslâm Ansiklopedisi. 18: 304-309. İstanbul: TDV Yayınları, 1998.

Topaloğlu, Bekir. "Kıyâmet”. Türkiye Diyanet Vakfı İslâm Ansiklopedisi. Ankara: TDV Yayınları, 2002.

Topaloğlu, Bekir - Çelebi, İlyas. “Acbü’z-Zeneb”. Kelam Terimleri Sözlüğü. 13. Ankara: TDV Yayınları, 2017.

Topaloğlu, Bekir - Çelebi, İlyas. "Ba's”. Kelam Terimleri Sözlüğü. 42. Ankara: TDV Yayınları, 2017.

Topaloğlu, Bekir - Çelebi, İlyas. "Haşir”. Kelam Terimleri Sözlüğü. Ankara: TDV Yayınları, 2017.

Toprak, Süleyman. "Haşir". Türkiye Diyanet Vakfi İslâm Ansiklopedisi. 16: 416-417. İstanbul: TDV Yayınları, 1989.

Tütün, Sevgi. Kur'an'da Hayat ve Ölüm Kavramları. Doktora Tezi, Dokuz Eylül Üniversitesi, 2005.

Yavuz, Yusuf Şevki. “Acbü'z-Zeneb”. Türkiye Diyanet Vakfi İslâm Ansiklopedisi. 1: 319. İstanbul: TDV Yayınları, 1989.

Yavuz, Yusuf Şevki. "Ba's”. Türkiye Diyanet Vakfı İslâm Ansiklopedisi. 5: 98. İstanbul: TDV Yayınları, 1989.

Yeşilyurt, Temel. Çağdaş İnanç Problemleri. Ankara: Diyanet İşleri Başkanlığı Yayınları, 2017.

Yıldız, Murat. Dinî Hayat ile Ölüm Kaygısı Arasındaki İlişki Üzerine Bir Araştırma. Doktora Tezi, Dokuz Eylül Üniversitesi, 1998.

Yılmaz, Engin. Said Nursî ve Elmalılı Hamdi Yazırı̀n Âhiret Anlayışı. Yüksek Lisans Tezi, Sakarya Üniversitesi, 2010.

Yılmaz, Kâmil. Tasavvuf ve Tarikâtler. İstanbul: Ensar Neşriyat, 2016.

Yılmaz, Sema. Çocukların Bilişsel ve Dini Gelişiminde Ölüm Olgusu. Doktora Tezi, Ondokuzmayıs Üniversitesi, 2011.

Yurdagür, Metin. Ünlü Türk Kelâmcıları. İstanbul: Marmara Üniversitesi İlahiyat Fakültesi Vakfı Yayınları, 2017. 